\title{
Improving purchasing performance by implementation of QMS process management approach in a manufacturing company
}

\begin{abstract}
Process oriented approach in quality management system has been introduced with ISO9001:2000. The international standard promotes the adoption of a process approach when developing, implementing and improving the effectiveness of a QMS to enhance customer satisfaction by meeting customer requirement. The advantage of process approach is to link all parties in scope of business of the organization from suppliers, internal departments of organization to gather to make B2B communication and integration. In this paper, the process approach is defined based on QMS requirement. Supply department was proposed for implementation of process. Purchasing process was designed as a linkage between supplier and internal company departments. Performance indicators were developed and measured accordingly. It shows that process management can improve delivery capability, quality and monitor price of supplied parts by suppliers.
\end{abstract}

Keyword: Business process management (BPM); Continual improvement; Key performance indicator (KPI); Purchasing; Quality management system (QMS) 